than ever. Poultices were discontinued, and the leather splint was reapplied.

July 26th. Operation. Under chloroform, Mr. Quain proceeded to excise the joint in the usual manner, by making an $\boldsymbol{H}$-shaped incision, and removing the patella and the ends of the femur and tibia. On removing the bones, the principal seat of disease, as had been anticipated, was found to be situated in the lower end of the femur; for, on cutting through the condyles, they proved to be softened and infiltrated with matter there existing also a cavity, of the size of a hazel-nut, filled with dark puriform matter. The head of the tibia and the patella were comparatively healthy; but the cartilages of the joints generally were very much eroded, and, in some places, altogether destroyed. There was little hæmorrhage, but a good deal of oozing from the cut bones, which continued for some time. Several points of suture were applied, and the limb bandrged to a straight back splint, with foot-piece and side flaps.

Aug. 1st. Since last note, the startings in the limb had continued as before the operation. Pressure was ordered to be made on the joint with plastic strapping and many tailed bandage. He continued to take full doses of opium at night.

A ug. ith. The startings in the limb had completely gone since the pressure was applied. The discharge was healthier; the wound was closing.

Aug. 13th. He was going on well. He was ordered to have seven minims of sesquichloride of iron in a mixture twice a day. He took also full diet, and eight ounces of wine.

Aug. 23rd. The wound on the outer side was closing rapidly; that on the inner side still discharged a good deal. It was ordered to be injected with an astringent lotion. His iron was changed to quinine.

Sept. 5th. Pressure over the joint was increased by applying strips of moist calico. No osseous union had, as yet, taken place.

Oct. 5th. During the last month, the size of the joint had decreased at the rate of nearly half an inch in circumference per week. The wound on the outer side was nearly closed; that on the inner side was looking healthier, but still discharged.

Oct. 10th. A leather cap was fitted to the knee to give additional pressure.

Nov. 2nd. The wooden splint was now removed, and two leather splints, reaching the whole length of the limb, were applied; by this means the patient was enabled to get about, on crutches. The joint was now pretty firm, and the wounds were reduced to mere points.

Nov. 30th. By help of a wooden clog to his boot, the patient could now get about, bearing on the limb. His health was excellent. He was now discharged.

Remarks. In his clinical lecture on this case, Mr. Quain made the following observations:-

"I have seen the term conservative applied, in some publications, to the treatment of disease of which this case affords an example; but I could not adopt that term, without implying that some other surgical treatment is destructive. Now, the operation is often unsuccessful; the mortality being, according to Mr. Butcher, one in five. But the results of amputation of the thigh, as you will see in your text-books, are very unfavour. able; thus, out of 143 cases, collected by Mr. Bryant (On Causes of Death after Amputation, Medico-Chirurgical Trans., vol, xlii), 39 proved fatal, or 1 in $3 \cdot 6$, which he divides in the following way :-

2. Amputations of expediency (deformities, etc.) 1 in 3.16

:3. Primary amputations $\ldots \ldots \ldots \ldots \ldots \ldots, 1$ in 1.5

4. Secondary amputations .............. 1 in 1.33

"It is not, therefore, a question between an unfavourable and a successful operation, for the mortality is about the same in both (the present case coming under the head of 'pathological'); but rather whether such a limb, as the operation of excision will leave, will not be more useful to the patient than any mechanical contrivance: I think it will.

"The operation itself is by no means difficult to be per. formed; there is no nice dissection; no important parts are involved; no large vessel or nerve is divided-none is even laid bare. The great evil is, that so large a surface of bone is divided and exposed to the air. You know how seriously a case of broken bone is complicated if the fracture is what is called compound, i.e. the integuments broken, and the fractured bones exposed to the atmosphere.

"I believe that the result of a case in which this operation has been performed, depends mainly, so far as the surgeon is concerned, upon the management after the operation; hence, in this case, I took every precaution that I considered necessary. I entrusted the care of it to a gentleman who paid the utmost attention to the diet, to the management of the apparatus applied to the limb; and to his careful management throughout I am disposed to attribute, in a great measure, the success of the case.

"There was much difficulty in managing his diet. After the operation, he craved for oysters. Wine-as much as eight ounces daily-and some beer, formed the main part of his nutriment.

"The pain which he suffered was quieted by the free use of opium, in doses varying from five to fifteen minims. The apparatus first applied was a straight board reaching from near the pelvis to the end of the limb, with a footpiece at right angles, and side flaps. After the free suppuration had ceased, and when the healing process at the wound was far advanced, long lateral leather splints were adapted to the limb; by means of this apparatus and bandages, as firmly applied as could be borne, the swelling at the knee, which was very considerable, even when the cicatrisation was advanced, was steadily diminished. You now see that it is little more than its natural size; that the cicatrix is sound; that the position of the foot is the same as that of the opposite side, the difference being that there is a shortness of the operated limb of about an inch and a half, which, considering the stiffness of the limb, will rather favour than impede his walking."

[The patient was in the theatre when these remarks were made.]

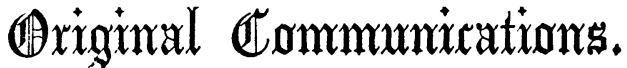

\section{A SKETCH OF THE HISTORY OF THE SURGICAL MEANS FOR ARRESTING BLEEDING FROM ARTERIES.}

By A. M. Enwards, F.R.C.S.E., Lecturer on Surgery. [From a Lecture delivered at a Conversazionc of the Royal College of Physicians of Edinburgh.]

Portal begins his celebrated History of Anatomy and Surgery with an apology for not stating the condition of these sciences before the Flood; it being, as he justly remarks, extremely difficult to separate fact from fiction in the traditions of those mysterious times. I must make the same apology. Neither shall I quote the tales of Podalirius and Machaon, and those names which bring our minds back to the old Grecian days; because we only hear of these renowned surgeons sprinkling styptics on wounds which, from the descriptions and the nature of the weapons inflicting them, seern to have been mere bleeding surfaces, or accompanied by that tearing and bruising which we know are so seldom followed by an excessive flow of blood. The very difference between arteries and veins, properly so called, not having been clearly defined till the time of Praxagoras, it is difficult to believe that there could have been any systematic method of arresting hæmorrhage before his time. Hippocrates, who lived more than a hundred and fifty years before Praxagoras, tells us that bleeding is stopped by fainting, position, obstructing the blood (elsewhere?), lint dressings, and bandaging. The obstructing was evidently accomplished in some way distinct from the bandaging other.

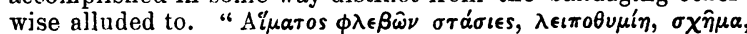

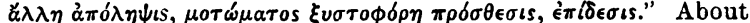
this passage there has been much dispute. Many commen. tators, as Iittré, note, tome v, p. 337, “qu'il s'agit d'autres choses que d'hémorrhagies." Galen quotes it as an enumeration of means proper for arresting hæmorrhages. Palladius thinks $\dot{\alpha} \lambda \lambda \eta \dot{\alpha} \pi \dot{\delta} \lambda \eta \psi(s$ applies either to some other means of arresting the flow of blood, or a peculiar proceeding, as ligature of the vessel wounded. Foës take the $\sigma_{\lambda \lambda \eta} \eta$ with $\sigma \times \hat{\eta} \mu \alpha$, and renders $\dot{\alpha} \pi \delta \lambda \eta \psi$ เs ligature of the vessel. M. Rosenbaum proposes to read $\alpha \lambda \lambda \eta, \tilde{a} \lambda \lambda \eta \eta$ set, and to render the words "arrest of the jet" (by the apposition of the finger), as he doubts Hippocrates knowing of the ligature. Archigenes, the celebrated physician of Philip, King of Syria, who went to practise in Rome about A.D. 108, says, in a fragment preserved by Oribasius, that, before an amputation, the part is to be bound tightly with a bandage, or the vessels bringing blood to the part are to be sewn together ( $\delta \iota \alpha \beta \beta \alpha \alpha^{\pi} \tau \omega$, to sew through or between); the 
words are rendered by Cocchius "vel consuenda vasa sunt". This has been generally considered a direction to tie the cut vessels; but Dr. Charles Wilson has directed my attention to the end of the passage, where Archigenes desires the surgeon, after completing the separation, to cauterise the raw surface with a hot iron, which would have been hardly necessary if he tied the cut ends of the vessels; moreover, he specifies the vessels bringing the blood to the part, therefore he most probably alluded to some means for obstructing the main vessels above the seat of the incisions.

However, in those days they seldom amputated; and, when they did, they took care to confixe their incisions to the dead parts, merely removing the gangrened mass, which, by its bulk and fotor, had become a nuisance; their dread of bleeding preventing interference with the living tissues. Celsus, indeed, more bold than his contemporaries, advises cutting just at the confines between the dead and the living; saying, however, that amputations are accompanied by great danger of the patient's dying during the operation from excessive bleeding: and, from what we know of the variable condition of the vessels close to a gangrened part, we can easily understand how on one occasion the incisions might be almost bloodless, and on another pour out sufficient blood to submerge the resources of those days. Yet Celsus knew of the ligature; because, in his chapter on wounds, he tells us to take up the bleeding vessel, and, having tied it in two places, to divide between them; if this is not feasible, the part must be burnt with a hot iron.

The "hot iron" was in those days quite identified with surgery. A surgeon was one who cut a little, and burnt a great deal; with the hot iron he treated all diseases. Hippocrates himself tells us that, in his time, cauteries had no terrors for the patients ; and that even those in health were occasionally fired. The nomadic Scythians got themselves cauterised on the temples, to counteract the disagreeable effects to the other end of their persons from their long and rough riding. This burning was the constant resource of the perplexed practitioner; but, in the fourth century, Oribasius expresses his distrust of cauteries; " they only", says he, "stop the bleeding for a time, and when the escar falls off it begins again more fiercely than before." But still he allows of their use in amputations. Time was evidently all they wanted; give them time, and I believe they would have tied the vessel much as we should now. When Paulus Agineta cut into an aneurism, he tied the artery above and below the sac; when he cut off a gangrened limb, his incisions were limited to the dead parts. Albucasis, who lived towards the end of the eleventh and beginning of the twelfth century, mentions four ways of arresting hæmorrhage. 1. Cauterisation. 2. The entire section of the bleeding vessel, its ends then contracting and retracting into the surrounding tissues. 3. The ligature. 4. The clot which forms at the orifice of a cut artery. It is curious to find an Arabian in the twelfth century instructing his disciples in the contraction and retraction of the cut arterial walls, and in the formation of the clot; the credit of which observation is given generally to Petit, who lived five hundred years later. And yet we find Albucasis saying that he thinks one method as good as another; and that it is far more safe to perform even small operations with a red-hot knife.

When surgery had struggled on for more than a thousand years, although physicians had attained to great glory, the people had ceased to appreciate the surgical attributes of fire and steel. A statue of gold had been raised to Hippocrates, and men like Oribasius had considerable influence in the national affairs; but equally great men, such as Archagathus, had been banished because they burnt and cut their patients. Antonius Musa gained honour, and a statue of gold, when a physician; but no sooner did he dabble in surgery, than the sovereign people thought fit to stone him to death and drag his body through the city. The priesthood were alone safe; and they being by the Council of Tours in 1163 forbidden to shed blood, the journeymen butchers, who acted under them, have not left any records as to how bleeding should be stopped, until after the schools of Bologna and Salerno began to send anatomists through the world.

Constantinus describes false aneurism as a frequent result of bleeding at the arm; and advises that pressure should be used on the ends of the divided vessel. Brunus of Padua applied a ligature to the cord when he performed castration. Lanfranc, a pupil of William of Salicetus, the first to disregard the veto of the Council of Tours, speaks of the hæmorrhages from wounds, and tells us that the blood issues in jets from an artery, but has a continuous flow when from a vein. "In either case the surgeon ought to put his finger over the opening in the vessel, and keep it there for an hour, thus giving the blood time to form a clot; after that, he is to use a powder made of incense, aloes, and hare's fur cut small, mixed with white of egg." This, he says, is a marvellous remedy, not only staying the blood, but healing the wound; if in spite of this, however, the bleeding should continue, then the vessel should be tied, as he had himself successfully tied the brachial of a young Milanese. In the fourteenth century, the cautery was again the favourite remedy. Each surgeon of repute had his own fashion of instrument. "William of Salicetus used six or eight forms of the cautery; Henricus seven; Lanfranc ten; and", says Guy de Chauliac, " $I$ have only six."

In 1503, Bologninus says: "The hot iron is too harsh a remedy for the patient, who, if he submits to it once, out of politeness to his medical adviser, won't stand a second application of it; but", says he, "I have a potential cautery I got from my father. Here it is; take three drachms of litilarge, hæmatite, and Roman vitriol, with two drachms of corrosive subli. mate. This is invariably successful."

In the sixteenth century lived John de Vigo, chief surgeon to Pope Julius II. He tells that, amputation being the only remedy for gangrene, you are to perform it with a well set razor; cut the flesh down to the bone, which you are to saw through; and then cauterise the raw surfaces with a hot iron. He suggests several other means for stopping hæmorrage from wounds, as styptics, and the ligature. 'The latter he does not seem to have used himself; but he says, "some are accustomed to tie the veins and arteries with a needle and thread, with which they constrict the walls of the vessel."

In 1534, Alphonsus Ferrius, a celebrated Italian physician, published his book on wounds: he was a man of great expe. rience, and his works bear the impression of a practised hand. He says: "When there is bleeding from a wound, stop it with caustics; if they fail, use the ligature. And the best caustic is made with two ounces of aloes, four of mastick, and one of hare's fur, made into a paste with white of egg. Cut this paste into several pieces, and add to each ounce $a$ drachm of corrosive sublimate to make it a caustic. Put a little piece over each bleeding vessel, and the hæmorrhage, if not very severe, will stop. But, if the cut vessel be of large size, the ligature alone can arrest it; and you must use it thus. Pass a thread, by means of a curved needle several finger-breadths long, pointed at one end, through the flesh, and, tying the thread tightly, you constrict the vessel."

This method was commonly practised in the sixteenth century. In 1563, Thomas Gale published in London his Enchi. ridion of Chirurgerie. He says: "To stay the flux of blood from a great vein or artery, we thrust a needle through that vessel, and knit the same with a thried; then draw out the needle, and the thried hang out so long until it falleth away... -You may also attempt to stay the flux of blood with bending the contrary side to the place wounded, or with letting of blood in another place, whereby there is diversion of the flux. If these suffice not, then you must apply causticke powderes, as arsenicum sublimatum, unslaked lime, and such like. And the cure that is here spoken of vaines, is also to be understand of arteries; and, the way to know whether a vaine or artery is wounded by the issuing out of blood. For, from a cut artery the blood cometh leping and springing out with sume staye according to the dilatation and compressyon of the artery." Gale had been with Henry VIII's army at MIontreuil in 1544, and with that of Philip of Spain, Qneen Mary's husband, in 1557 , at the siege of St. Quintin. He does not specially mention tying the vessels after amputation, and prefers his "causticke powders" to the hot irons, which, he says, "sore feared the people, so that many would rather dye with the member on than abyd by the terrible fire, by means whereof many perished."

To do them justice, however, they had great delicacy about these instruments of torture. "Your patient", says 'Turner " especially if a woman or child, or a woman with child, should never be allowed to see or know of your irons."

When we consider that Gale and his contemporaries passed their " thried" under the vessel, including more or less of the surrounding tissues, and that they had no idea of its being able to do more than mechanically constrict the canal; and as serious results must have resulted now and then from such a coarse proceeding, it does not surprise us that they looked upon the ligature as a simple and obvious device, but a bar barous and dangerous practice, fitted only for emergencies.

In the early part of the sixteenth century, however, a wholesome competition was beginning in Paris between the surgeons of the Long Robe, who were Masters of Arts, and those of the 
Short Robe, who had been originally barbers, and who, from bleeding and tooth-drawing, had ventured on the more important operations. They were also granted the title of barbersurgeons, to distinguish them from their more dignified but less practical brethren of St. Côme. In Italy, where one might have expected better things, only nine years after Ferrius had published his famous work upon wounds, recommending the ligature, Blondus published in the same town (Naples) a work enlarging upon the frightful dangers of hæmorrhage, and recommending, as a styptic, a paste made of equal parts of bole Armenian, vitriol, hare's fur, verdegris, incense, cobwebs, etc., etc.; quoting Ferrius largely, but never alluding to the ligature.

But Ambrose Paré, the future champion of this, the simplest and the best of our surgical instruments, at this time arrived in Paris, and joined the Barber-Surgeons' Company. He followed the French army into the field in more than one campaign, and early showed an aptitude for his calling. "And the physicians admired me, to see ne so ready in the operation of chirurgery, seeing the small age I had." Whenever he met with one pos. sessing some reputed specific, he managed to obtain it from him. At Thurin, he found a chirurgeon who had fame above all others for curing of gun-shot wounds. "After keeping me off for two years, in the end by gifts and presents he gave it to me: it was this, to boyle young whelpes new pupped in oyl of lillies, prepared earth-worms and turpentine of Venice. Having obtained this receipt of his baume, I was joyful, and my herrt was glad."*

Paré soon found that cauteries were not available in military as in civil practice. "In the assault of a city, where diverse soldiers have had arms and legs shot off by bullets, cutlasses, or other instruments of warre, if you should use hot irons to stay the fluxe of blood, it would be needful to have a forge and much coals to heat them." And he adds, "The souldiers would hold you in such horror, that they would kill you like a calf." Infuenced by these motives, and having read John de Vigo's book, he adopteed the plan of tying the arteries; and, on his return to France, advocated its being generally used instead of the cautery. He gives the following directions for amputating: - "Drawing the muscles upwards to the sound parts, let them be tied with a straighte ligature a little above that place of the member that is to be cut off with a strong and broad fillet, like that which women use to tie up their hair withall. This hath a twofold use: first, it liolds up the muscle with the skin; second, it prohibits the fluxe of blood. When you have made your ligature, cut the flesh even to the bone with a sharp and well cutting knife; when you shall come to the bone, you shall nimbly divide it with a little saw. When you have taken away the member, the ends of the vessels lying hid in the flesh must be drawn with this instrument (a forceps) forth of the muscles; and when you have so drawn them forth, bind them with a strong double thread."

As is well known, this innovation in practice brought the surgeons of the long robe down upon Pare; and pamphlets were published sbowing " how arrogant and indiscreet a person he was to blame and condemn the cauterising of vessels after the amputation of a rotten and corrupt member, which had been much praised by the ancients."

Pare had no theory by which to explain the advantages of the ligature; and it became a mere question of experience. So he demonstrated his method to the fraternity in Paris, and published the cases. "In the year 1583, a man, having his leg all ulcered, prayed me for the honour of God to cut it off; so, after his body was prepared, I caused his leg to be cut off four finger breadths below the knee by one of my servants, to embolden him in such works. The vessels were easily tied, in presence of John Charbonell, Master Barber-Chirurgeon of Paris. He was well cured, God be praised; and is returned home to his house with a wooden leg." The heads of Colleges took it very ill that one little better than "un vil barbier" should so vigorously advance his views on any subject, and they entreated the public not to listen to one who, it was clear, could know nothing of the subject, as he was ignorant of Latin. They ran him very hard; and he turned at last on his chief persecutor, Gourmelin, saying, " Have I not studied long in the hospitals? Have I not been in many battles, and shut up with many wounded men in besieged towns? And how dare such a man as you, who have never made surgery a part of your study, talk of teaching me? .... Ah ! you ought not to speak unluckily of one who all his life hath preferred the profit of the commonwealth to his own particular?"

How fortunate for him was all this persecution! He is now

* I quote from the early English edition of his werks. very generally considered the discoverer of the ligature; while we have seen that it was in use from the earliest times. No doubt, his is the first special mention of it, as applied to am. putations; but such an obvious method of closing a compressible tube as tying it must have existed ever since the blood-vessels of man were subject to accident, and there was any material for a ligature.

While Pare was fighting for the ligature in Paris, Maggius was advancing very different doctrine at Bologna-namely, that after an amputation you should dip the stump in boiling oil, either by itself or mixed with melted sulphur. He modified the steps of the operation. "The modern surgeons," he says, "with an instrument which has the form of a large knife, cut and burn the flesh, veins, and arteries, at the same time. But we cut the soft parts with a sharp knife, and then insert an instrument like a scythe into the wound, with which we press on the bleeding surfaces till the bone is sawn through, after that we burn the ends of the vessels with irons having olive or globular extremities; then spread over the wound gums fit for holding wounds together." $\mathrm{He}$ is very strong against the red-hot knife used by his contemporaries. "If 1 were otherwise" says he "I should be flying in the face of Celsus, contradicting Galen, and making Hippocrates, the father of physic, tell a lie." $\mathrm{He}$ mentions that, notwithstanding their tight bandaging when the amputation was completed, blood gushed from the veins and arteries in great quantities. Maggius' treatment of bleeding stumps, by placing heavy dressing on them, and then drawing the skin tightly over the end, shows that surgeons were now beginning to depend to some extent on immediate pressure. In support of this treatment, he alludes to the custom of the Venetian liciors, who, when about to cut off the hand of a criminal, first drew up the skin as much as possible, and, after dismembering, drew it as tightly down, then sticking the bleeding stump into the belly of a dying fowl. Dr. Balfour tells me that he has seen, in China, a living pigeon split up, and applied to a cut throat.

In England, the surgical customs with regard to hæmorrhage were probably imported from Italy. The resemblance of Gale's remarks on the needle to those of Ferrius must have been remarked; and, moreover, the English chirurgeons were not remarkable for originality. John Bannister, of London, in 1578 , when recommending his book "to all godly surgeons," says, "it is sucked from the sappe of the most approved anatomists."

There was nowhere, at this date, an efficient tourniquet; and yet so anxious were they to be independent of the cautery that occasionally they tried Guy de Chanliac's method of inducing gangrene by tight bandages, so that the limbs dropped off, and immediate pressure by some waterpoof material, as a bullock's bladder pulled tightly over the stump. In 1600 , Fabricius (ab Aquapendente) thus describes removing the female breast:- "When it is moveable, it must be amputated. I seize it with pincers, and cut the breast off with one sto a red-hot knife. This method is painful; if the cancer be adherent, and you cannot pull it up, you must cut it with a sharpened piece of horn or wood, dipped, in order to prevent bleeding, in the fluid by which artificers separate gold from silver, called by the vulgar aqua fortis. Having cut the skin through with this all round the gland, dig the latter out with your nails." This surgeon sometimes burnt off limbs rather than risk a possibly fatal hæmorrhage. At this date, too, Severinus was using tile actual cautery, first applying to the raw surfaces alum and white of egg. At this time, too, the doctrine of the sympathetic powders was in vogue, and Becker, first physician to the Elector of Brandenburg, wrote a thick book on its mysterious virtues.

In 16i 6, Wiseman makes this remark-" If you work (amputate) there by actual cautery with a hot knife, your knife will stick fast in the flesh till the moisture be wholly dried up, and then you must repeat many knives and cauteries, with every one of which you will meet with the same inconvenience. Yea, before you can cut through with your hot linite it is very probable that you will near the bone meet with some parts that are alive and sensible." $\mathrm{He}$ amputated two fingers' breadths above the gangrened part thus:- "The member is to be supported by some one, whilst another standeth behind the patient, and draweth up the skin and musculous flesh." The ligature was placed round the limb by him, apparently as a tourniquet. "Other chirurgeons in our city (London) omit it; they only make a turn with a tape, pinning it on as a mark to circumcide by. And, instead of the ligature, I propose they make a gripe, which gripe is commonly made by some assistant who hath strength to do it. . . . I never yet saw any man so gripe 
but that still the artery bled with a greater force than was allowable; yea, when Mr. Woodall griped, who was so applauded, and in truth made for the work. And then," says he, "what if the long griping tires the griper?" After the amputation, " you are at liberty, whether you will cuuterise the vessels by a button cautery, or by ligature stop the bleeding, or by agglutination. The use of chalcanthum I do not approve."

The way Hildanus proposes, by drawing the vessels out by a forceps, is not a work to be done in the heat of fight, nor without a clear daylight. "Ambrose Parè proposes a more easie and sure way of deligation, by passing a needle with a strong twisted thread through the skin near the great vessells, making your stitch over the said vessels by piercing through the raw flesh and skin. 'Then make your ligature on the fold of a rag ; thus you bind the artery and vein."

In 1685, we find the great Dutchman Anthony Nuck condemning the ligature, and recommending the puff-ball mushroom for the bleeding in amputations; the efficiency of this remedy depending mainly on the manner in which it was piled up over the bleeding vessels, and on the tight bandages which fixed it. In 1781, a French army surgeon, Morel, seeing how carriers tightened the ropes fastening bales of goods on their carts, applied the principle in surgery. This father of all tourniquets was simple enough, consisting merely of a pad stuffed with hair, a strong bandage, an ell and a half long, a stick of rough wood, and a piece of leather with on each side a cut for the passage of the bandage. With the stick he twisted the bandage tight, and thus obtained the desired power over the circulation; his apparatus continued in use till Louis Petit invented another. Notwithstanding all this, Verduc, a celebrated surgeon of Toulouse, eleven years after Morel's invention, amputated with a block, a mallet, and a chisel, cauterising the vessels with a small iron.

In 1698, John Coldbatch, a I ondon physician, published his Novum Lumen Chirurgicum. He had followed the army in Flanders four years before, and his book gives us a good idea of the surgical practice in his day. Like his brethren, he had wonderful nostrums of his own to recommend; and he does so the more confi iently " as, after bleeding from wounds, not one in ten recovels in the common methods of the chirurgeons. When any large blood-vessel is wounded, the flux of blood cannot be stopped by them without either actual or potential cauteries, and they are not to be trusted without very strict bandage, which always, or at least for the most part, causeth mortifications, and loss of limbs and life;" whereas he (Cold. batch) "merely maketh a solution of his powder in water, for want of which he sometimes useth urine; and having applied the said solution to the wound, he keeps his hand over any large artery that may be cut, till the flux of blood ceaseth."

We can form some idea of the practice from this case :-

"Mr. Lorridge, a lieutenant in the Honorable Brigadier Lumley's regiment, received a slight wound under the right armpit; the axillary artery being pricked, the blood from which was soon stopped or rather pent in by Mr. English, chirurgeon to the regiment. After a month, he had a fresh flux of blood, and, from what I saw in his bed and his breeches, he lost seven or eight pounds of blood. 'The surgeon's mate stopped it with a very straight bandage; but it beginning again, the most eminent surgeons were about five hours endeavouring to stop the flux of blood, but could not, though using many hot irons. I found him in a most deplorabie condition; his arm swelled up in a most prodigious manner from the bandage," and the novum lumen chirurgicum only arrived in time to light him out of the world.

Coldbatch was allowed by Mr. Cooper to experiment on some amputation cases, at St. Bartholomew's, before about thirty doctors; upon which occasion he confesses that "several applications had to be made before the fluxes could be stopped. But after our patients were dressed, we all went to the tavern and spent the evening in very great satisfaction at what we had done."

His treatment resembled that of the sympathetic doctors; adjusting the parts carefully, using water dressing, and keep ing up the patient's strength with good living and wine. "Any wine is good," says Coldbatch, " but old hock I find best."

Returning to the continent, we find, in 1696 , Peter Verduin, of Amsterdam, amputating with a flap, and using a sort of retinaculum to press on the stump, which, he says, saved the trouble of securing the vessels.

The tirst real advance towards a thorough knowledge of hæmostatics was made in the year 1700 , by a Scotsman, James Kiel, who, after travelling on the continent, settled in Northampton. He gives a clear account of the three tunics of an artery, and how they depend for support upon the smalb vessels of the outer coat. He died from cancer of the lip, aged 46 , and in the meanwhile the ligature had almost died out. When Valsalva endeavoured to revive it in $17(14$, most men had quite forgotten it.

In the beginning of the eighteenth century, surgeons, dis. gusted with the hot irons, and afraid of the ligature, were more in favour of immediate pressure, which was apparently perfected for amputation in Petit's screw-tourniquet for pressing on the end of a stump.

But superstition, or whatever it is called, influenced the public at this time. They took to amulets made out of the right ear of an ass; they tried to act on the imagination by tying live toads under the armpits and the soles of the feet As of old, they attempted to divert the flow of blood by bleed ing in some distant part of the body, by cupping, or by strong frictions, as Gale recommended. At other times, they en deavoured to retain a reserve fund of blood by tightly bandaging the upper part of one leg or arm. The more practical, desiring immediate pressure, set about obtaining it by the most extraordinary means. Hares' fur and cobwebs had lost their influence, and were superseded by the moss scraped from deac men's skulls. "Common moss," says Wolfius, "is of no use and that which grows in the skulls of criminals (crania suspensorum) is of most service to the physician," especially if the scraper had been used in some murderous deed. Styptics, generally caustic solutions, appeared from time to time. 'Th eau de rabell, so famous in France and Germany, was merely strong sulphuric acid and spirits of wine.

In the reign of Charles the Second, Mr. Dennis's essence made a great noise, and he was desired, not without a princely reward, to communicate his secret. It was prepared in the royal laboratory, and used with great applause as the stypticum regis; but afterwards, the secret taking air, it turned out a most painful and violent caustic, at the same time quite ineffectual as a styptic.

In 1737, Anel revived a styptic that had been ushered in with great pomp in $16 \tau 4$, by Yonge, an English surgeon, in the Currus Triumphalis, or the admirable virtues of Oleum Tercbinthinc. It is still in use, and I believe is a very excellen styptic for bleeding surfaces. The good things imported into England at all events stayed there. So far back as 1682, Dr. Salmon directs that if the flux from an artery be great, the bes way will be to cut it in two, and then cauterise it with a button of vitriol, or else take it un and tie it, and then cauterise it. Agaric was a favourite application till 1755, when Parke advised that the ligature should be substituted for it; and in 1757 it was brought before the Academy of Paris. That learned body reported that there was nothing very specific in its virtues, as it required to be applied to the vessel with great and accurate compression, which, they suggest, may possibly have as much effect as the intrinsic qualities of the agaric itself, and they seemed to think that scraped lint would do nearly as well. It was used in the form of small balls, which were pressed on the vessels.*

In 1757, Lawrence Heister frequently alludes to this immediate pressure. "If," says he, "you wound the brachial artery when bleeding from the arm, do not get confused by fear, lest the patient or his attendants suspect your error: tell the patient his blood is so lot and redundant, that a large evacuation is necessary. Let him bleed till he faints; and then, when neither he nor his attendants are minding you, place a farthing or some other piece of money in the folds of compress, and bandage it on the arm, signifying to the bystanders that the patient's blood is so rapid and ardent that it cannot well be restrained without this particular deligation. Thus, perhaps, your error may escape unsuspected; and, if you haven't got a farthing, a lump of brown paper chewed in your mouth will do as well."

In giving directions concerning amputation, he desires the surgeon not only to have his forceps ready for the arteries, but also bits of blue vitriol wrapped upon lint or cotton, astringent

* MMr de la Fage, Hoin, et Moreau, s'en sont servis très-utilement dans l'opératiou de l'anneurisme au bras, sans avoir lié l'artère. M. Andoilié l'a loperation de langen tatioye de meme, dans deux cas parells, et a rétssi dans plusieurs ampatation d' la jambe. Mais l'on pourrort dire que lagarie appliqué a li jábe, l lavant bras, meme au bras, n'a rien si mervelleux pour arreter les hemornagies, parceque que le topique ayant besoin d une compression sûre pour avoir son effet, cetce compression nécessair pour lapplication utile de agaric, peut contribuer à arreter l' hemorrhagie presqu'autant que l'agaric reme guoting a work published by Felix Wurt an ancient trentise on surgery ing bo tome iii, 1757.) 
powders to stop the hæmorrhage, and a piece of the fungus called lupi crepitus, or puff-ball. However, he desires also that the tourniquet (Morel's) should be in use, with a stick which an assistant held behind the operator, at his desire turning off or on the stream of blood.

It is evident that Heister tied the larger vessels only, and stopped bleeding from the smaller by caustics and compresses. One would imagine that, having a tourniquet to give them time, and ligatures for securing the vessels, surgeons required nothing more; but they still wavered from one remedy to another, as accident, or caprice, or opportunity influenced them. They could not explain why the ligature should be the most efficien means ; and, indeed, it had the disadvantage of a foreign body left in the wound. Dessault first remarked that the internal coat of an artery was cut by a ligature tightly applied to it, but he made no practical use of this observation.

We have seen, in the end of the seventeenth century, John Kiel, a Scotchman, endeavouring to elucidate the subject of lıwmostatics by careful study of the arterial tube itself. And in later times, a Scotsman, Dr. Thomson of Edinburgh, demonstrated to Dr. Jones the effects of a ligature upon the arterial walls and the process of repair after they are injured. These are now universally known; and ever since surgeons have been given these good reasons for the greater efticiency of the ligature, they have become as constant to it as before they were fickle. It is now the rule, and not the exceptional practice. No real surgeon now dreads bleeding from any vessel, if it be within his reach and he can cast a noose round it; but he no longer, like Ferrius, includes the surrounding flesh, or, like Dessault, the adjacent vein ; nor does he limit the practice to the larger arteries, but, isolating any vessel inclined to bleed, he ties it alone, knowing that even the smallest has in itself the real materials for its own repair.

Many devices have appeared from time to time, with the object of avoiding the ligature's only drawback-the foreign body in the wound, and the small slough contained in its noose. Torsion of the vessel, so as to divide the inner and middle coats, and leave the outer lacerated like a hood over the mouth of the vessel till inflammatory changes in the others have taken place, had its turn, and won a share of popular favour. But the amount of twisting to which we must subject an artery of any size, lills the part so twisted, and it is thrown off as the little slough is which we draw out with the ligature. From time to time the material of the latter has been altered.

The ancient practice of using metallic threads, revived by Levret in 1829, and now so generally employed for sutures, has not in this country extended to their use as ligatures; indeed, they would only avoid one drawback of the silk, or hemp, or other ligature; the sloughing part of the vessel would still bave to be thrown off.

The most important novelty in the means for arresting bleeding, is Professor Simpson's acupressure-wedging the vessel between its surrounding tissues and a pin introduced from the skin surface of a flap, and removing the pin in from twenty-four to forty-eight hours. The great advantages to the wound of removing any foreign body from within it at such an early period are obvious. And I can bear witness, from cases treated under my own notice by this method, to the ease with which the pins are applied, their efficiency in arresting bleeding, not only from the main vessels, but from oozing surfaces, and the saving of time in the cure from the causes above mentioned.

Substances Found in Snow. It would seem, from a paper read before the Academy of Sciences on March 5th by M. Pouchet, that snow is not so pure as is generally supposed. He there stated that he had made a special examination of some snow collected on March 21th at Rouen, and had there found the following substances:-particles of carbon from smoke; starch-granules (of which some were observed to be coloured blue, as by iodine); a green orgaric matter, some. times in irregular plates, sometimes in ovoid grannles; granules of silica and of calcareous matter; encysted infusoria or ova, bacillaria, etc. ; grains of pollen; jointed filament of equisetum (?) ; spores of lycoperdon (?); filaments of wool, etc. M. Pouchet, however, did not find, at least in any number, sporules of plants or animal ova. This latter statement has a benring on some observations which M. Pouchet has been lately making on the subject of the spontaneous or non-spontaneous development of the simpler forms of organised beings.

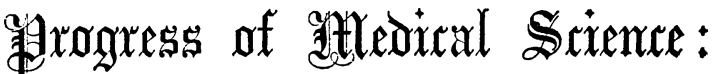

\section{AT HOME AND ABROAD.}

OPHTHALMIC SURGERY.

LOCALISED GALVANISM AS A REMEDY FOR THE PHOTOPHOBIA OF STRUMOUS OPHTHALMIA.

WE reprint from the American Journal of Medical Sciences for January 1860 an interesting paper by Dr. ADDINELL Hewson, of Philadelphia :-

Intense photophobia constitutes the most prominent and characteristic symptom of the ophthalmia of strumous children, and is undoubtedly one of the chief causes of the obstinate and troublesome character of the diseases of the eyes in that class. The constant avoidance of the daylight, and, consequently of fresh air, both of which are so essential to overcome the peculiar constitutional taint of such cases, and the incessant fomentation to which they subject their eyes by burying them in their pillows, clothes, or handkerchief's saturated with their tears and perspiration, for days, weeks and even months together, not only tend to aggravate all the symptoms of the disease, but to protract them indefinitely, and, in many instances, to render the eyes incurable.

In the poor children brought to the dispensaries connected with the ophthalmic hospitals, the early relief of this symptom is of the utmost importance. Amongst them, the worst cases are those who have intemperate parents, and who are, consequently, neglected and exposed to the worst hygienic influences. For such it is worse than useless to prescribe iron, bark, codliver oil, and other eutrophics, to be administered at home, for much valuable time will be lost waiting for the benefits expected to be derived from such remedies, as they will scarcely ever be given. Even the injunction to keep the child's face uncovered, and to give it fresh air to breathe, will not be attended to. Indeed, I am firmly convinced, from no little observation in the matter, that whatever benefit is to be derived from attempts to treat these cases at their homes, must be by remedies applied or administered by the medical attendant himself. I have, therefore, always tried by means of local applications, to afford them as early relief as possible from this photophobia, so that they would, of their own accord, seek the light and air, the best remedies within their reach at home for their recovery, and I have always found improvement in all the other symptoms to follow the relief of this one. Even in private practice, and amongst the best classes, where every comfort, luxury, and attention that wealth can command are brought into requisition, we often meet with cases which seem to receive no benefit for weeks or months, but, on the contrary, grow worse notwithstanding the most faithful and skilful use of a great variety of constitutional remedies, until the photophobia is relieved by remedies applied especially for that purpose, when the child will begin to run about, and its convalescence become rapidly confirmed. The question might be asked here, Is not the abatement of the photophobia in the latter cases rather the first sign of the yielding of the disease to constiturather the first sign of the former the result of improved health ? In many instances of strumous ophthalmia, such may be the case, but not so in the instances to which I have reference; for I refer to those in which the health was steadily failing in spite of constitutional remedies, or in consequence of the administration of such remedies being neglected, and in which the relief of the photophobia followed so rapidly the use of special remedies directed for that purpose, as to leave no doubt of the cause of such relief or of the modus operandi of the remedies. My impressions of the good effects of these remedies have been so strong as to induce me to test them very critically for several years. I have thus tried blisters and tincture of iodine to the forehead and temples, vapours of various kinds (especially that of muriate of ammonia) directly to the eye, local and general anæsthesia, belladonna, and a variety of other articles. The benefits to be derived from the most, at least, of these remedies, have long been known to the profession. I shall, therefore, not comment upon them at present, but on the contrary, confine myself to a brief exposition of the results which I have obtained from another remedy, the application of which I believe to be altogether novel. I refer to galvanism localised to the supra.orbital branch of the fifth pair of nerves, which has thus far proved to be the most efficient remedy I 